\title{
EL CONCHERO DE "CAÑADA HONDA" (ALJARAQUE, HUELVA): ESTRATEGIAS PREDATORIAS Y MODELOS EN TRANSICIÓN
}

\author{
THE SHELL MIDDENS OF "CAÑADA HONDA" (ALJARQUE, HUELVA): \\ PREDATORY STRATEGIES AND TRANSITION MODELS
}

\author{
por \\ JOSÉ MARTÍN GÓMEZ \\ PEDRO CAMPOS JARA
}

RESUMEN El análisis de la transición de sociedades cazadoras-recolectoras a productoras, entendido como proceso histórico, nos lleva, entre otros factores, a profundizar en las consecuencias de la intervención del hombre en la génesis y desarrollo de los recursos alimentarios.

En el contexto del suroeste peninsular, el conchero de Cañada Honda (Aljaraque, Huelva), situado en el estuario de los ríos Tinto y Odiel, se presenta como un yacimiento clave tanto en el estudio del modo de vida de estos grupos, como en el de la adopción de ulteriores formas productivas, así como en el de la definición de la secuencia poblacional de la zona.

\begin{abstract}
The transition from hunting gathering societies to producers ones' analysis, understood as an historic process, takes us, between others factors, to deep in human intervention's consequences inside genesis and development of alimentary resources.

Inside Peninsular south west context, at shells' deposit of Cañada Honda (Aljaraque, Huelva), placed at Tinto and Odiel rivers' stuary, appears as a main site for the study of these groups' ways of life, as well as for the adoption of the ulterior production's ways, and also in that referred to the poblacional sequence of the zone's definition.
\end{abstract}

\section{INTRODUCCIÓN}

En el horizonte de la prehistoria onubense, englobable también en esto en el área del suroeste peninsular, faltan, por utilizar una imagen de historia como devenir, evidencias de algunos momentos concretos que le dan al cuadro cronológico-histórico un aspecto de discontinuidad, lógicamente más explicado en función de la parcialidad del registro (no olvidemos que buena parte de los restos aparecen casualmente, cuando lo hacen) que de una demografía cambiante. 
Ahora bien, no es ésta la única argumentación válida para entender el fenómeno. Más aún, la causa fundamental puede hallarse en un ámbito diferente, que entendemos más cercano a problemas teóricos o metodológicos de partida. En esta dirección, la aplicación de lo que podríamos denominar "modelos culturales", especialmente en lo que se refiere al bagaje tecnológico (aspecto más evidente y, por tanto, más utilizado), no basados en el contexto inmediato, sino de alguna manera "importado" y, por ello, a veces, extraño al espacio geográfico y temporal que manejamos, puede desvirtuar hasta tal punto el resultado de un análisis que la imagen resultante es, antes que falsa, falseada.

Es por ello que él estudio de la prehistoria tiende, cada vez más, a basarse en modelos de interpretación regional. Se trataría de establecer un primer escalón en el proceso de conformación global.

¿Cómo se concreta esto en la problemática que analizamos? Ya advertíamos que la falta de elementos en el conjunto histórico deviene más de problemas teóricos que de lo aleatorio del proceso de constatación de cualquier ítem arqueológico. De hecho, la aplicación de modelos regionales importados, convertidos erróneamente en paradigmas, determinan esos espacios en blanco. Por entendernos con un ejemplo sencillo, si pretendemos analizar la flora mediterránea en base al catálogo de especies ecuatoriales podría llegar a la conclusión de que nuestra región, botánicamente, es una zona muerta.

Entendemos que el fantasma de la atomización tipológica que tanto asusta a algunos investigadores ha de quedar atrás si, en primer lugar, se utilizan aquellas que no partan de una lista cerrada de tipos (más o menos amplia, pero que siempre muestra un modelo irrepetible aunque varíe el número de adiciones posteriores), sino de la definición de una serie de caracteres morfológicos y morfotécnicos, mensurables, conforme a una relación abierta y especificada. Lógicamente, en este tipo de sistematización de un conjunto industrial deben evitarse nomenclaturas que impliquen funcionalidad. Ello sólo será aceptable cuando tal finalidad haya sido demostrada mediante el análisis de las huellas de uso. En este caso, pasará como una variable más, fuera de la consideración estrictamente tipológica, a la definición global de la industria. En segundo lugar, nos abstenemos de establecer comparaciones entre conjuntos industriales como medio de definir culturas o pueblos. Esto último sólo tiene sentido si las variables que entran en la comparación incluyen el modo de producción, la normativa cultural y la carga tecnológica en relación al ecosistema, geotemporalmente localizado, en que se haya inserto cada grupo. En todo caso, es ésta una problemática que aparcamos para su estudio más detallado en otra ocasión. De hecho, en el presente trabajo habremos de adaptarnos a los estudios realizados; continuaremos aquí, pues, en espera de un posterior replanteamiento más pausado y global, utilizando la terminología que podemos considerar normativa al uso.

\section{EL MANHATTAN PALEOLÍtico}

En buena medida determinado por el exitoso trabajo llevado a cabo en el yacimiento, supuestamente inferopaleolítico, de El Aculadero, se inicia una cadena de hallazgos de industrias líticas en el litoral suroeste que acaban siendo clasificadas en idéntico periodo. Venía a corroborar así una temprana ocupación del litoral andaluz por poblaciones provenientes de África, que habrían cruzado el estrecho de Gibraltar extendiéndose después, tanto siguiendo la línea de costa como penetrando hacia el interior a través de los diferentes valles fluviales, especialmente el Guadalquivir y Guadiana (puerta de entrada, este último, en la Meseta).

Sin que queramos invalidar este movimiento migratorio como origen de la ocupación de este área por parte del hombre (discusión que queda fuera del ámbito de este trabajo y para cuyo planteamiento carecemos de datos), sí que hemos de poner en duda la atribución, hecha a la ligera, que databa en el 
Paleolítico Inferior o Medio cualquier industria lítica litoral de aspecto arcaico. Ni siquiera somos los primeros en hacerlo.

La pequeña broma que constituye el título de este apartado nos llevaba a afirmar que si todas las industrias líticas "arcaizanes" del litoral occidental onubense pertenecieran a aquel periodo, tendríamos aquí una densidad de población paleolítica tal cual la del Manhattan actual.

Lo cierto es que, aún hoy, del análisis del catálogo de yacimientos prehistóricos onubenses publicados se desprende una ocupación, especialmente centrada en los cursos del Tinto, Odiel y sus tributarios, durante el Paleolítico Medio, desapareciendo cualquier evidencia de poblamiento posterior hasta el momento representado por las ocupaciones neolíticas prelitorales. Se aprecia así un hiato de grandes proporciones en las que una de tres: o no había nadie para dejar vestigios, o no se han hallado aún estos, o están ahí delante y se han clasificado equivocadamente. Esta última posibilidad, la que más adelante defenderemos, ha sido insinuada ya por diverso arqueólogos, sin que hay llegado a plasmarse en una propuesta de trabajo presentada. Baste como ejemplo de esto que afirmamos lo expresado por D. Enrique Vallespi (Vallespi y otros 1981 pág. 23) sobre lo dudoso de atribuir apriorísticamente al Paleolítico Inferior todas las series de cantos tallados aparecidos en el litoral onubense, o, más recientemente, la más comprometida referencia contenida en la obra de D. José María García Rincón (García Rincón 1988) sobre el corte de "La Glorieta" y la posible relación de las industrias de cantos onubenses con las industrias tardías portuguesas, hablándose ya con claridad de una atribución fini o postpaleolítica. Atribución mejor definida en Portugal, donde los trabajos de Raposo, Peñalva o Carlos Silva (por citar sólo algunos), han contribuido de forma importante a plantear interrogantes adecuadas para una mejor dirección de los estudios sobre las industrias macrolíticas fini o postpaleolíticas.

\section{UNA EXPLICACIÓN INICIAL}

No nos es ajeno el modelo de coexistencia de diferentes conjuntos industriales en un mismo contexto geotemporal. Aparcando de momento si ello es referido a la existencia de pueblos diferentes con modelos socioeconómicos distintos, o muestra de actividades diversificadas realizadas por un mismo grupo humano en función de cuestiones como la estacionalidad u otras, podríamos señalar, por su coincidencia con la hipótesis que pensamos desarrollar, el ejemplo cantábrico como el que puede reflejarla mejor.

Las industrias de cantos tallados del litoral onubense responden, por lo general, a una serie de características comunes susceptibles de ser analizadas desde diferentes perspectivas. Por hacer, grosso modo, una relación de las más llamativas tendríamos, por una parte, su carácter superficial. En efecto, hasta la fecha no ha aparecido ninguno de estos conjuntos en conexión estratigráfica. Por otra, sus particularidades morfotécnicas, determinadas, aparte de por condicionantes funcionales, por las propias cualidades de la materia prima mayoritariamente empleada, la cuarcita, que no permite un trabajo tan elaborado como el sílex, confiriendo, de por sí, un aspecto más "arcaico". El proceso de talla, extremadamente simple, tiende a la consecución rápida del útil, por encima de una posible mayor productividad en relación con la sofisticación técnica. A primera vista, la cadena tiempo de consecución de la materia prima, tiempo de elaboración, tiempo ahorrado en función de la productividad de la herramienta, parece decantarse hacia un mayor ahorro en los dos primeros factores, decidido, seguramente, por la menor contribución del tercero al proceso global.

Tipológicamente predominan los cantos tallados uni y bifaciales, las lascas de descortezado, de semidescortezado y ordinarias, todas ellas mayoritariamente no retocadas, y los núcleos, generalmente 
centrípetos, con o sin preparación periférica previa. La presencia de útiles, clasificables como tales, es porcentualmente baja y poco significativa.

Hasta ahora, las atribuciones que se han hecho, a partir de estas escasas consideraciones, basadas tan sólo en el análisis tipológico y tipométrico de las piezas líticas, apuntaban una economía fundamentada en el aprovechamiento de los recursos marinos (marisqueo y pesca) complementado con la caza y la recolección. En todo caso, la no constatación hasta el momento de significativas acumulaciones de restos de alimentos, tales como conchas o huesos, implicaba, junto al carácter fuertemente disperso de toda la industria por el litoral, por un lado el carácter poco estable de los asentamientos (sin prejuzgar que futuros hallazgos hagan cambiar este panorama) y, por otro, la no vinculación directa de lo que se viene denominando como talleres con áreas de actividad predatoria.

Sin romper ese esquema, por cuanto la simple distribución espacial, en torno a las desembocaduras de ríos sin penetración hacia el interior, nos lo muestra como alternativa no sólo lógica sino tal vez única, se hace necesario considerar, dado el tipo de costa con que nos encontramos, abiertas y arenosas, con las únicas excepciones de los estuarios, que las tareas de recolección de moluscos, actividad económica presumible, habrían de realizarse con un tipo de utillaje que, a diferencia de lo que pueda ocurrir en zonas como el Cantábrico, donde rocas y acantilados dan lugar a un tipo de malacofauna que necesariamente requiere para su recogida objetos contundentes (picos asturienses, v. g.), debe estar adaptado a la penetración más o menos profunda en bancales arenosos. Para este tipo de actividad, la madera resulta mucho más adecuada. A modo de primera conclusión (a corroborar lógicamente mediante estudios funcionales y de huellas de uso) tendríamos pues una industria lítica utilizada como elemento secundario en el proceso de obtención de alimento.

\section{LA CUESTIÓN DEL MIRENSE PORTUGUÉS}

Hace ya unos años que investigadores del país vecino vienen desarrollando trabajos en torno a las industrias líticas litorales. Lamentablemente, esas líneas imaginarias que trazamos sobre el territorio y que llamamos fronteras consiguen a veces lo que las barreras naturales no habían logrado anteriormente. Así, salvo esporádicos contactos ', no ha habido un verdadero engarce entre los estudios a un lado y otro del Guadiana. Hemos llegado incluso hasta el extremo de que se haya dedicado mayor extensión a las posibles relaciones entre las industrias portuguesas englobadas bajo el término Mirense y las marroquíes definidas como Tensiftiense, que a la existencia de un continuum de aquéllas por todo el litoral suroccidental español, necesario para establecer la relación estudiada.

Si exceptuamos el trabajo de García Rincón (García Rincón y Vidal Rodríguez 1988), poca cosa más se ha hecho en esa dirección. Se hace necesario un planteamiento radicalmente contrario si queremos llegar a definir con precisión el mundo que representan las industrias tardías de cantos tallados.

El principal inconveniente para el establecimiento de una relación permanente entre ambas zonas ha podido resultar del uso de una terminología diferente (que no un idioma). Así, prácticamente toda la caracterización del Mirense portugués giraba en torno a un fósil director cual es el machado mirense. Definido como un útil tallado generalmente sobre lasca o fragmento de canto de cuarcita, en el que pueden distinguirse dos partes diferenciadas, una distal (o cabeza), más larga y tendente, generalmente, hacia la forma de una espátula, y una proximal (o mango), más estrecha, concebida para facilitar su aprehensión manual o su enmangue (Raposo y Penalva 1991), se trata en todo caso de un tipo no constatado en los yacimientos onubenses.

1. Por ejemplo, el Encuentro Internacional de Arqueología del Suroeste (Huelva, 1994). 
El resto de los elementos definidores de las industrias mirenses, tanto en lo que se refiere a caracteres morfotécnicos como en cuanto a la distribución espacial e, incluso, a las formas de asentamiento (si exceptuamos la falta aquí de lo que se denominan campamentos, en base a la existencia de estructuras de combustión), son prácticamente coincidentes.

Ahora bien, la reciente publicación de Luis Raposo (1994) sobre el yacimiento de Palheiroes do Alegra, en que se defiende la concreción del Mirense como “(...) una, 'civilización', epipaleolítica del VII milenio, estrictamente confinada a la franja litoral y fuerte concentración: de lugares entre el Cabo de Sines y la playa de Zambujeira", individualiza excesivamente, desde nuestro punto de vista, en un marco cronológico-geográfico estrecho, una manifestación económicocultural cuyos ejes fundamentales, a saber, la caracterización morfológica y morfotécnica de la industria lítica y la localización litoral, tienen una manifiesta continuidad -englobadas para su estudio en las "industrias de base macrolítica"- en momentos neo/calcolíticos, e incluso del Bronce. Continuación resuelta por algunos autores (v. g. Carlos Silva 1994) con el planteamiento de la disyuntiva entre la posibilidad de que supongan "manifestaciones tardías de una tradición tecnológica fuertemente condicionada por la naturaleza de la materia prima disponible y por las necesidades objetivas de cariz económico en ámbitos específicos", y aquella otra que apuntaría hacia "realidades tipológicas diferenciadas entre las que, una lectura demasiado empírica, establece una relación (cronológica cultural) reductora o distorsionada de la realidad".

Entendemos que, más allá de caracterizaciones nominales, el estado actual de las investigaciones permite comenzar a hablar con propiedad de una continuidad cierta de las industrias macrolíticas (o de cantos tallados) del litoral. Continuidad que, con las características reiteradamente marcadas, nos muestra una realidad socioeconómica de larga tradición, basada esencialmente en factores de estabilización, geológicos, económicos y culturales, capaces de prolongar en el tiempo estrategias predatorias de aprovechamiento económico del medio, apoyadas en una tecnología concreta, a las que se irían sumando otras, en última instancia de carácter productor, cuyo impacto, atemperado en principio por los factores estabilizadores de que hemos hablado anteriormente, supone el germen de contradicciones en el sistema, cuya resolución dará lugar a un cambio profundo en las estructuras socioeconómicas, $y$, con ello, en todo el bagaje tecnocultural de que se sirven.

Explicaciones del tipo de aquellas que intentan establecer una diferenciación entre yacimientos costeros macrolíticos o de "cantos tallados", por una parte, y "concheros", por otra, basadas en la inserción, en el primer caso, en un marco ecológico determinado por el menor nivel del mar y en consecuencia la vastedad del territorio de captación de recursos, lo que unida a la escasa presión demográfica incidiría en la no sobreexplotación de los recursos, sobreexplotación que sólo se presentará con posterioridad dando lugar a las significativas acumulaciones de restos de moluscos que encontramos en el segundo caso, no resuelven satisfactoriamente la problemática fundamental.

Y ello es así porque, a nuestro entender, de esta forma se obvia uno de los elementos que podrían, tal vez, aportar mayor luz sobre la compleja problemática que estamos tratando. De hecho, si aceptamos la cronología propuesta, "concheros" y lugares de ocupación "macrolíticos" podrían haber compartido idéntico espacio geotemporal. Al menos durante una parte del periodo total de existencia de la cultura de cantos tallados tardíos del litoral, ambas manifestaciones convivieron. Establecer las claves de relación, ya sean genéticas, de sustrato, o manifestaciones de diferentes actividades dentro de una misma comunidad, ayudaría a resolver la problemática de la transición de sociedades cazadoras-recolectoras a las productoras. En este contexto, atribuir a un modelo demográfico diferente el tipo de aprovechamiento de recursos distinto que, aparentemente, representan los lugares de ocupación y actividad "macrolíticos", y los concheros epipaleolíticos, supone establecer de antemano su desconexión, pese a que, como hemos visto, han podido compartir idéntico tiempo y espacios próximos, cuando no 
coincidentes. Es una dirección de estudio que nos parece necesitada de una mayor profundización, al tiempo que de un giro en sus planteamientos teóricos y metodológicos. Algunos esquemas tradicionalmente propuestos apuntaban una simplista línea de explicación basada en la secuencia: subida del nivel del mar, reducción del territorio de aprovisionamiento, mayor presión demográfica, cambio en las costumbres nómadas, surgimiento del modelo de explotación representado por los concheros. Sin embargo, esta simple concatenación de elementos, por sí, no explica satisfactoriamente todos los interrogantes que se nos pueden plantear. Así, cuestiones como el cambio de la industria lítica, con aparición de tipos nuevos sin base genealógica, el grado de sedentarización que implican los concheros, y la relación de estos últimos con el paso a formas productoras, no están en absoluto zanjadas. Ello por no hablar de la movilidad de los grupos y la consiguiente extensión por el litoral suroccidental (y hasta África, como ya hemos visto) de las industrias que los caracterizan.

\section{EL YACIMIENTO TIPO CONCHERO DE "CAÑADA HONDA": HACIA LA FORMULACIÓN DE UNA HIPÓTESIS PLAUSIBLE}

Faltaban, hasta ahora, dentro del panorama arqueológico de la provincia onubense, yacimientos de tipo "conchero", como los existentes en Portugal. Es un fenómeno que podemos conectar con la falta de evidencias epipaleolíticas. Ausencia especialmente significativa si aceptábamos la hipótesis propuesta por varios autores que establecía una relación causal entre el epipaleolítico geométrico de los yacimientos portugueses y los levantinos, representados por Cocina, y cuya vía de expansión, en la alternativa que nos ocupa, sería la del litoral andaluz, como lo muestran los yacimientos de Nerja y de La Caleta.

Con el panorama apuntado, es fácil entender que la aparición de una importante ocupación fluviomarítima con modelo de explotación de tipo "conchero" en Huelva puede contribuir de forma trascendental a la aclaración de buena parte de las interrogantes que podemos plantear sobre el periodo que tratamos.

Por ello, y aun con carácter meramente preliminar, entendemos importante dar a conocer la existencia de tal localización por cuanto ese solo elemento puede dar lugar a un replanteamiento profundo de los estudios sobre la transición a la economía productora en el área suroccidental de la península ibérica.

\section{El Ecosistema}

El conchero de "Cañada Honda" se sitúa sobre un nivel de terraza del río Odiel a $+4 / 5 \mathrm{~m}$, en la margen derecha, a unos $2,5 \mathrm{Km}$. de la antigua estación ferroviaria de Corrales.

Su ambiente actual es de marisma, teniendo como curso de agua principal más cercano al Caño del Fraile, uno de los brazos del Odiel que, aguas más abajo, forman la ría de Huelva.

Estas marismas de la costa atlántica andaluza constituyen en la actualidad una importante zona húmeda del Golfo de Cádiz. Se hallan enclavadas en depósitos de edad Neógeno-Cuaternario de naturaleza detrítica, los cuales han servido tanto de sustrato como de área fuente para su relleno (Viguier 1974).

Su evolución geomorfológica durante el Holoceno, periodo que nos interesa, ha sido estudiada por diversos autores (Figueroa y Clemente 1979; Clemente y otros 1985; Ojeda 1989) siendo sus conclusiones básicamente coincidentes. Así, partiendo de la última regresión finipleistocena, hace unos 18.000 años aproximadamente (Paskoff 1985), la ría de Huelva estaría ocupada por lechos fluviales de carácter torrencial que arrastraban materiales gruesos (cantos y gravas) procedentes en su mayor parte de la remoción del glacis de acumulación (Cuaternario antiguo) (Clemente y otros 1985). Todo ello dentro 
de un marco general en el que el descenso en el nivel de base y el aumento de las precipitaciones, asociadas en nuestras latitudes a las pulsaciones frías, supuso, lógicamente, el aumento de la capacidad erosiva de la escorrentía superficial cuyos principales cauces excavaron profundos estuarios que hoy en día encuentran prolongación en la plataforma continental, a la vez que, con este proceso se desmantelaban parte de las formaciones pliocuaternarias recientemente emergidas (Ojeda Zujar 1989). En aquellos momentos, tanto el curso del Odiel, como el del vecino Tinto, se prolongaban sobre una plataforma continental que llegó a alcanzar una anchura de $40 \mathrm{Km}$. (Melieres 1969; Igme 1974), con el nivel de base situado a 110/130 m. por debajo del actual (Clemente y otros 1985).

La fundición de los hielos supuso en nuestras costas la invasión por las aguas marinas de aquellos estuarios y la conformación de una costa recortada, con numerosos entrantes y salientes sobre los que los agentes morfodinámicos comenzaron un lento proceso de regularización hasta nuestros días. La denominada transgresión Flandriense supuso entonces, en su máximo transgresivo (7500 BP), un posicionamiento del nivel relativo del mar unos $2 \mathrm{~m}$. por encima de su posición actual (Ojeda 1989). El estuario del río Odiel alcanza la latitud de Gibraleón y la ría de Huelva queda transformada en una amplia bahía con una fuerte influencia marina.

A partir de ese momento, los aportes continentales comienzan a sedimentarse en el fondo de los entrantes, descendiendo el espesor de la lámina de agua; lo que unido a la acción de la deriva litoral, concretada en la formación de barras litorales, determina la progresiva disminución de la influencia marina, que de todas maneras continúa siendo clara al menos hasta el $3.000 \mathrm{BP}$ (Clemente y otros 1985). Esta progresiva evolución estaría controlada, pues, por la actividad de unos agentes morfodinámicos cuyas características serían muy similares a las actuales, dado que no parece probable que se haya producido, desde entonces, un cambio sustancial en el régimen del clima marítimo.

Los únicos estudios sedimentalógicos de que disponemos, los efectuados por Menéndez-Amor (Menéndez-Amor y Florschutz 1964) y, más recientemente, por Horowitz (Blanco Freijeiro y Rothenberg 1981), ambos basados en el análisis de las turberas de la Laguna de las Madres, en las proximidades de Mazagón, nos muestran una vegetación más abundante, con menor presencia de pino que hoy en día, dentro de un ambiente climático más húmedo y con nivel de agua subterránea más alto que el actual, independientemente del nivel del mar, durante el periodo Atlántico.

\section{La Localización (fig. 1)}

Hallado por uno de nosotros (P. C. J. ) en el transcurso de trabajos previos a la elaboración de una carta arqueológica de Aljaraque, el conchero se halla, como ya hemos apuntado, sobre una terraza del río Odiel. Aparece cortado transversal y longitudinalmente. En el primero de los sentidos, en su vertiente sur, por trabajos de explotación de grava que, a tenor de los restos hallados, en el borde opuesto de la extracción, debió arrasar al menos un cincuenta por ciento de la superficie total. En la segunda dirección, el corte, más antiguo, se realizó para facilitar el tendido de la línea de ferrocarril minero que baja desde la cuenca de Tharsis hasta Corrales.

Sin tener en cuenta esas modificaciones introducidas recientemente, originalmente el asentamiento se emplazaba sobre una pequeña elevación cortada al norte por la denominada "Cañada Honda", extendiéndose por la pendiente suave que desciende hacia el río. La superficie que se conserva aún ronda los 800 metros cuadrados.

Su estructura interna, mostrada en los cortes antes mencionados, revela una aglomeración de restos de moluscos, mezclados con algunos fragmentos óseos, menos abundante, y con gran cantidad de 
industria lítica. Todo el paquete aparece muy compacto por efecto de la disolución de carbonato cálcico, lo que le da una consistencia cementada.

A priori, la simple observación superficial de los cortes no muestra una estratificación clara. Ello puede deberse a la antigüedad de los mismos, que, especialmente en el caso del ferrocarril, puede remontarse a bastantes años. En todo caso, sólo una limpieza del perfil podría, tal vez, aclararnos, aún fuera inicialmente, la estratigrafía del conjunto.

No podemos dejar de apuntar, por lo que pudiera representar en cuanto a la existencia de estructuras de habitación u otro tipo, la presencia de fragmentos de arcilla endurecida, similares a los mencionados por Roche en su trabajo sobre los concheros del Muge (Roche 1965).

\section{La malacofauna}

En una primera aproximación a la malacofauna del yacimiento de "Cañada Honda", hemos procedido, igual que, como luego se explicará, se hiciera con la industria lítica, a realizar un muestreo superficial, sin recogida, que ha permitido identificar las siguientes especies de moluscos:

\section{a) Bivalvos:}

\section{1) Orden: Pterioida // Género: Crassostrea angulata}

Las especies actuales de este género se producen en aguas con amplios límites de salinidad. Pueden vivir incrustadas en las rocas o sobre conchas de la misma especie. Se trata de un género cosmopolita.

\section{2) Orden: Veneroida // Género: Venerupis pullastra}

Algunas especies viven enterradas en fondos fangosos, arenosos o de gravas, hasta $200 \mathrm{~m}$. de profundidad. Otras se fijan a objetos sólidos y existen algunas que habitan en el interior de grietas, lo que produce deformaciones en la concha.

3) Orden: Veneroida // Género: Cerastoderma edulex y glaugun

Las especies actuales pueden vivir en aguas de distinta salinidad, sumergidas en sedimentos fangosos o arenosos generalmente a escasa profundidad.

\section{b) Gasterópodos}

1) Orden: Mesagasterópodos // Género: Cerithium rupestre

Marino, sobre fondos preferentemente duros, con abundante vegetación, a escasa profundidad.

2) Orden: Neogastrópodo // Género: Murex brandaris y trunculus

Marino, vive sobre todo a escasa profundidad.

Por tanto, las características generales de la malacofauna nos apuntan hacia un medio con amplios límites de salinidad, poca profundidad, con presencia de fondos fangosos, arenosos y de gravas, aguas cálidas y, como señalan especialmente los gasterópodos, vegetación abundante. Se trata, en cualquier caso, de un cuadro global asimilable a las características que hemos apuntado en el análisis evolutivo. 


\section{La industria lítica (figs. 2 y 3 )}

Como ya hemos dicho, la industria lítica del yacimiento es muy abundante, pese a lo cual, y de cara a esta primera comunicación, no se ha hecho una recogida sistemática ni intensiva. Nos hemos limitado a la constatación de tipos y a establecer a grandes rasgos los porcentajes en que aparecen, efectuando diversos muestreos superficiales y del paquete, sin recogida de útiles, que han sido, en todo caso, descritos y dibujados in situ. Con base en las características inicialmente observadas podrían resumirse así:

- Abundancia extraordinaria de restos de talla: lascas sin retocar, núcleos, esquirlas y fragmentos diversos; todo lo cual nos demuestra que las tareas de preparación del material lítico se han llevado a cabo en el propio asentamiento.

- Tendencia general hacia el microlitismo, reflejado especialmente en la importante cantidad de laminillas, en las correspondientes huellas de extracción de los núcleos prismáticos y en la presencia, hasta ahora, de un único geométrico.

- Diversidad en los tipos. Hemos podido constatar la presencia de raspadores, denticulados, muescas, laminillas retocadas y estranguladas, amén de un único buril y el geométrico antes mencionado.

- Predominio del retoque abrupto; aunque hemos de mostrarnos prudentes puesto que, dada la escasez de la muestra, sólo supone una valoración provisional.

- Significativa presencia de cantos tallados a pesar de su relativa escasez.

- Gran variedad en las materias primas utilizadas, en apariencia locales, obtenidas por el aprovechamiento de los nódulos y cantos de la gravera. Es de señalar que, para los útiles, se prefiere el sílex.

La relación detallada de los principales elementos líticos recogidos en este primer muestreo son los siguientes:

- Un buril simple distal desviado, con dos facetas, sobre lasca de sílex. Dimensiones en mm.: $31 \mathrm{x}$ $16 \times 10 \mathrm{~mm}$.

- Una raedera lateral sobre lasca de sílex: $25 \times 22 \times 7 \mathrm{~mm}$.

- Un raspador frontal sobre lámina retocada, talón fracturado y señales de uso: 52 x 16 x $10 \mathrm{~mm}$.

- Un raspador carenado sobre lasca de sílex: 27 x 16 × $8 \mathrm{~mm}$.

- Un raspador denticulado sobre lasca de roca silícea.

- Una laminilla (en la frontera con las láminas) en sílex de doble dorso truncada, de bordes muy irregulares, cercana a denticulado en su lateral izquierdo y a muescas en el derecho.

- Una lámina en sílex, de doble dorso y muescas, verdadera lámina estrangulada.

- Una lámina en roca silícea, con muescas mediales en ambos bordes laterales, semejante al caso anterior aun faltando en ésta el dorso rebajado.

- Un geométrico en sílex; pieza a medio camino entre un triángulo isósceles y un segmento de círculo. La fractura de uno de sus extremos dificulta su adscripción concreta a uno u otro grupo.

Destacan además siete fragmentos de laminillas en sílex de diversas coloraciones, de sección triangular en la mayoría de los casos, alguna con señales de uso en sus bordes; y tres fragmentos de láminas, también en sílex. Una de ellas, con dorso natural y abundantes huellas de uso en su filo, semejante a un cuchillo de dorso reservado.

Completan la muestra de la industria lítica cuatro núcleos para laminillas en sílex de diversas tonalidades, uno de ellos piramidal muy agotado, siendo el resto: uno prismático, uno multipolar con 
huellas de extracción también de lascas y un ortogonal con dos orientaciones; una lasca sobrepasada, producto de un accidente de talla debido a la existencia de un plano de esquistosidad en un núcleo para laminillas en sílex; y dos cantos tallados unifaciales.

\section{La problemática}

Hasta ahora, la localización de "Cañada Honda" es la única de su tipo documentada en la margen derecha de la ría del Odiel. Nosotros mismos hemos hallado pequeños concheros tanto en la margen izquierda, a la altura de Gibraleón, como en la rivera de Nicoba, tributario del Tinto, en las proximidades de Peguerillas; sin embargo, a falta de su estudio, hoy por hoy no podemos afirmar que se trate siquiera del mismo momento. En cualquier caso, la escasa industria lítica documentada, sin recogida ni análisis detallado, en el primero de estos yacimientos permite, al menos, suponer cierta relación.

Con este panorama, se hace difícil engarzar "Cañada Honda" en el proceso histórico que ha tenido como marco el tramo final del Odiel. Ello, no obstante, no impide que, el simple planteamiento de qué. representa, pueda conducirnos a dibujar, a modo de problemática a abordar, su inserción en una cuestión que viene siendo objeto de estudio por quienes suscribimos el presente trabajo: el proceso de génesis y consolidación de estrategias productoras. En efecto, entendido éste como aquel que permite a los grupos de cazadores recolectores llegar (por sí o a través de contactos) a la adopción de estrategias de producción ${ }^{2}$, ya hemos tratado en otra ocasión (Campos y Martín 1994) la importancia que para ello tiene, en esta zona, el optimo productivo alcanzado a partir de la explotación predatoria de un espacio amplio, particularmente rico y vinculado, además, con un componente de estabilidad (en este caso el mar) que, mediante la introducción de un elemento fundamental, tal como es la semisedentarización, suponga, al mismo tiempo, una situación previa favorecedora de la adopción de tales estrategias y un "retraso", fundamentalmente debido a la falta de elementos de presión sobre un sistema relativamente estable, de la sustitución del componente recolector, básicamente, por ellas.

En una dinámica de este tipo, las estrategias predatorias convivirían con las productoras. Aquellas aportarían una fuente de nutrientes segura y estable. El mayor peso de la actividad recolectora de moluscos implicaría la necesidad de completar la dieta con alimentos de origen vegetal. La introducción entonces de las estrategias de producción destinadas a ello cerrarían el ciclo alimentario adecuadamente y por ello serían adoptadas.

Ahora bien, el cultivo de vegetales conlleva la necesidad de prever la creación, mediante almacenamiento, de una reserva destinada a compensar su carácter de aporte estacional. Este concepto de "reserva" es, como hemos señalado ya (Campos y Martín 1994), esencial, desde nuestro punto de vista, para entender cómo esa situación de óptimo productivo, enmarcadà además en una dinámica de renovación constante con base en el potencial marino, contiene en sí el germen de la contradicción básica del sistema. A saber, la consolidación de relaciones de jerarquización en función del control del proceso de dosificación-distribución del componente destinado, en principio, a solventar las deficiencias, principalmente estacionales, que hayan podido ser producidas por la pérdida, aun deliberada, de la movilidad permanente como fórmula para evitar ese mismo carácter estacional.

2. Preferimos la expresión estrategias de producción antes que el de economía productora por cuanto entendemos que ésta debe reservarse para aquellas formas de explotación del medio en las que resulta dominante. En las que suelen calificarse como de transición, más aún en los estadios iniciales donde aparece como un elemento cuantitativamente menos importante, consideramos que su aparición no puede determinar, ni siquiera nominalmente, el modelo económico en su conjunto. 
En esa línea, la variante que intentamos contrastar vendría dibujada por la aparición, a partir del elemento de distorsión señalado, de la necesidad de conversión en excedentes de aquellas reservas iniciales, por presiones inherentes al propio desarrollo del modelo socioeconómico. Establecer si tal explicación pasa por la concreción secuenciada del proceso en asentamientos del tipo "Cañada Honda", "Casa del Río" y "Papa Uvas", es básicamente nuestra preocupación en estos momentos.

\section{BIBLIOGRAFÍA}

BLANCO, A. y ROTHENBERG B. (1981): Exploración Arqueometalúrgica de Huelva (EAH). Barcelona. CAMPOS, P. y MARTÍN, J. (en prensa): "El poblado de "Casa del Río", Aljaraque (Huelva): su aportación a la definición de formaciones sociales protoproductoras con estructuras de reservas". Cuadernos del Suroeste 4.

CARLOS, A. (1994): "Problemática das “industrias macrolíticas" do Guadiana (Un tema a nao ignorar para uma maior aproximaçao ao estudo do povoamento pro-histórico no interior alentejano" En Arqueología en el entorno del Bajo Guadiana. Huelva.

CLEMENTE, L.; MENANTEAU, L. y RODRÍGUEZ VIDAL, J. (1985): "Los depósitos holocenos en el estuario de los ríos Tinto y Odiel (Huelva, España)". En Actas de la I Reunión del Cuaternario Ibérico. Lisboa.

FIGUEROA, M. E. y CLEMENTE, L. (1979): "Dinámica geomorfológica del Estuario de los ríos Tinto y Odiel (Huelva). Aplicación a la ordenación del territorio". En IV Reunión Nacional para el estudio del Cuaternario. Bañolas (Girona).

GARCÍA RINCÓN, J. M. (1988): "Informe del sondeo estratigráfico de urgencia de La Glorieta". En Anuario Arqueológico de Andalucía; Urgencias. año 1985, Consejería de Cultura de la Junta de Andalucía. Sevilla.

RODRÍGUEZ VIDAL, J. (1990): "El sondeo estratigráfico de La Glorieta (Punta Umbría. Huelva)". En Huelva Arqueológica XII.

INSTITUTO GEOLÓGICO Y MINERO DE ESPAÑA (1974): "Investigación minera submarina en el subsector 'Huelva I'. Golfo de Cádiz". Ministerio de Industria. Madrid.

MELIERES, F. (1974): Recherche sur la dinamique sédimentaire du Golfe de Cádiz (Espagne). Univ. Paris VI. Tesis Doctoral.

MENÉNDEZ-AMOR, J. y FLORSCHUTZ, F. (1974): "Resultados del análisis paleobotánica de una capa de turba en las cercanías de Huelva (Andalucía)" En Estudios de Geología XX.

OJEDA, J. (1983): "La dinámica litoral reciente en la costa occidental de Andalucía". En El Cuaternario en Andalucía Occidental. AEQUA Monografías.

GILES, F. y SANTIAGO, A. (1988): "El poblamiento del sur de la Península Ibérica en el Pleistoceno Inferior a través del Estrecho de Gibraltar" En Congreso Internacional "El Estrecho de Gibraltar". Madrid, UNED.

PASKOFF, R. (1985): Les littoraux. Impact des amenegements sur leur evolution. Ed. Masson.

RAPOSO, L. (1994): "O sitio de Palheiroes do Alegra e a 'Questao do Mirense'”. En Arqueología en el entorno del Bajo Guadiana. Huelva.

PENALVA, C. (1993): "Les haches Miriennes du Portugal et les houes Tensiftiennes du Maroc: Quel type de relation?". Actas do I Congresso Mediteríanico de etnologia historica. Mediterraneo 2. Lisboa. 
ROCHE, J. (1965): Balance de un siglo de excavaciones en los concheros mesolíticos de Muge. Madrid. RUIZ COBO, J. y MONINO, M. (1987): "Los yacimientos de conchero en la costa cántabra". En Revista de Arqueología 73. Madrid.

THIBAULT, C.; QUEROL, M. A.; VIGUIER, C. y SANTONJA, M. (1977): "El yacimiento del Paleolítico Inferior Arcaico de "El Aculadero" (Puerto de Santa María, Cádiz)”. En XIV Congreso Nacional de Arqueología. Zaragoza.

VALLESPÍ, E.; AMO, M. y ÁLVAREZ G. (1981): "Primeras evidencias paleolíticas de la provincia de Huelva". En Huelva Arqueológica $V$.

VIGUIER, C. (1974): "Le Néogene de L'Andalousie nort-occidentale (Espagne)". En Histoire Géologique du Bassin Guadalquivir. Burdeos. 


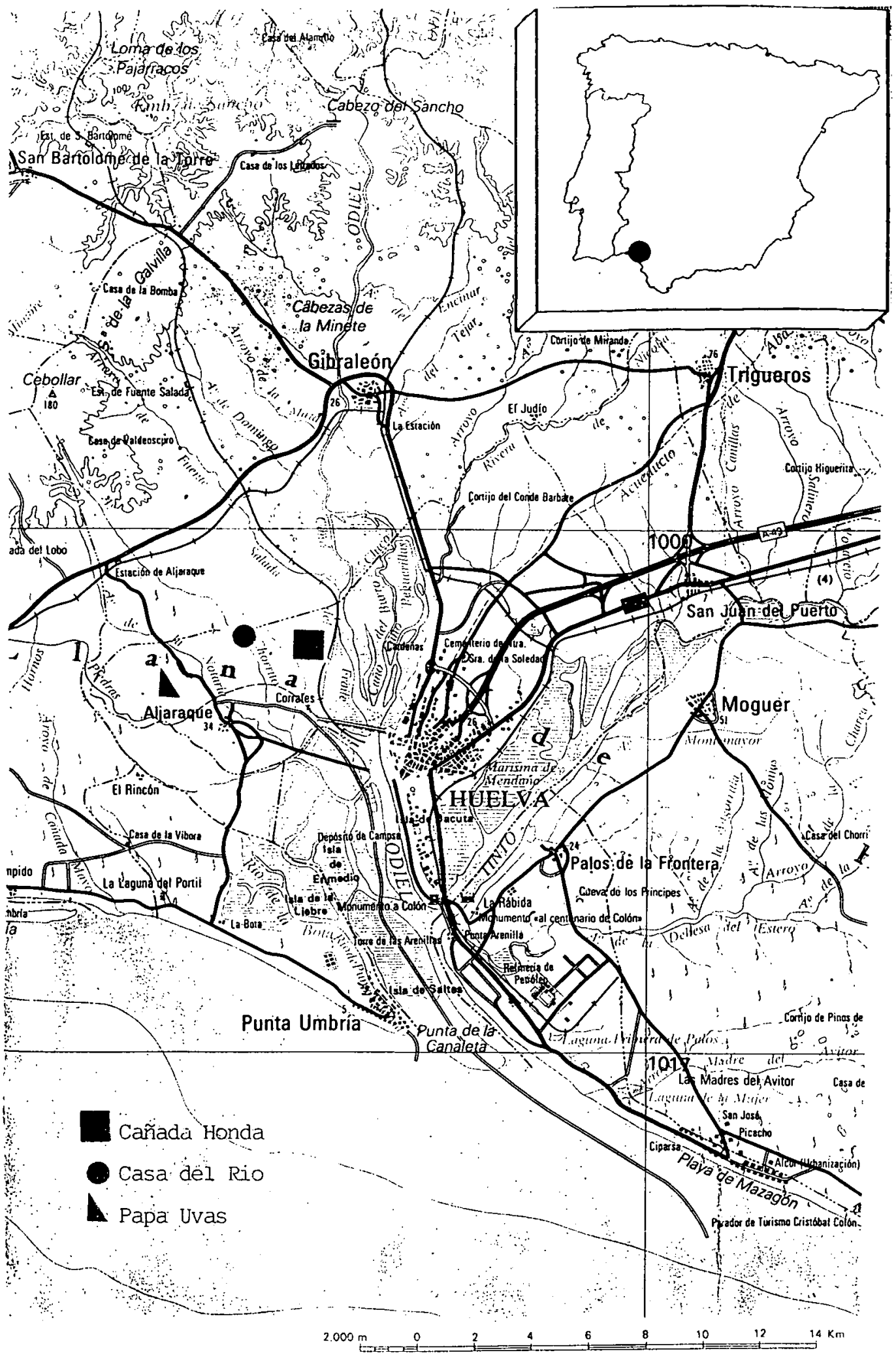

Fig. 1: Cañada Honda. Localización geográfica 


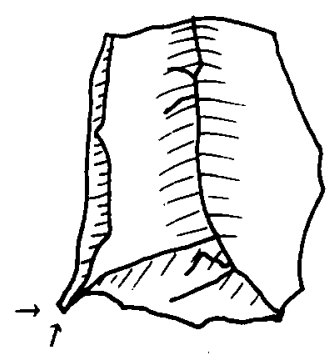

A

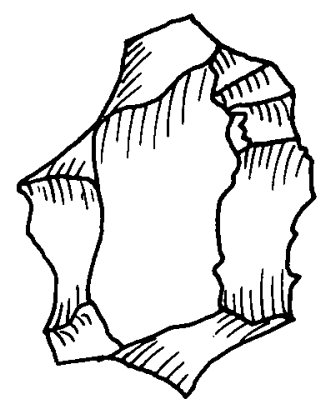

E

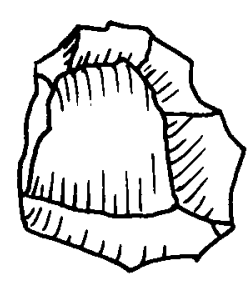

B

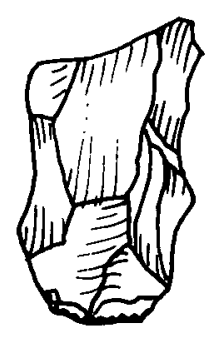

C

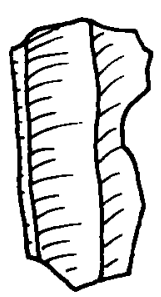

G

H

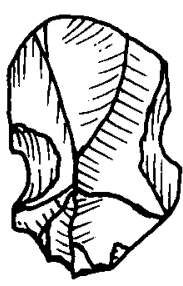

D

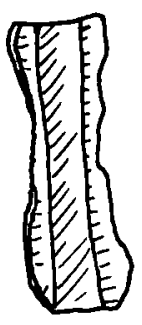

$\mathrm{F}$
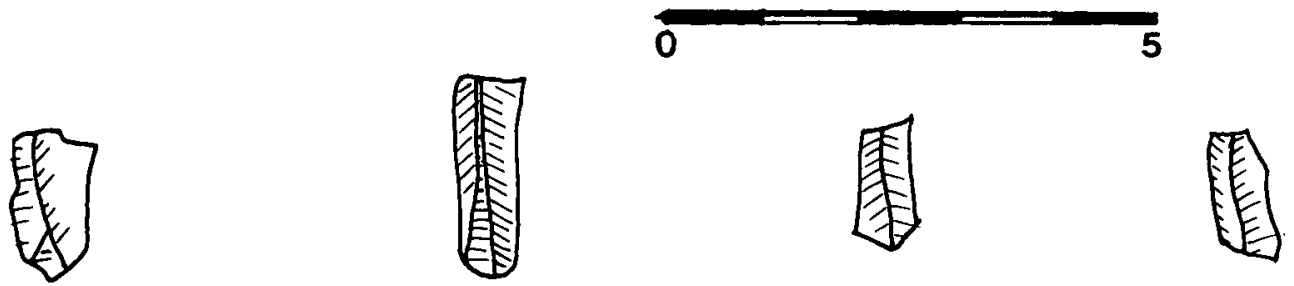

$\mathrm{K}$

L

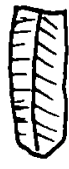

M

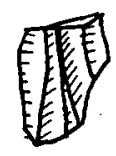

N

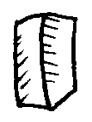

$\bar{N}$

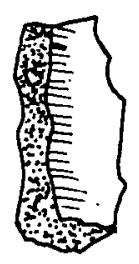

O
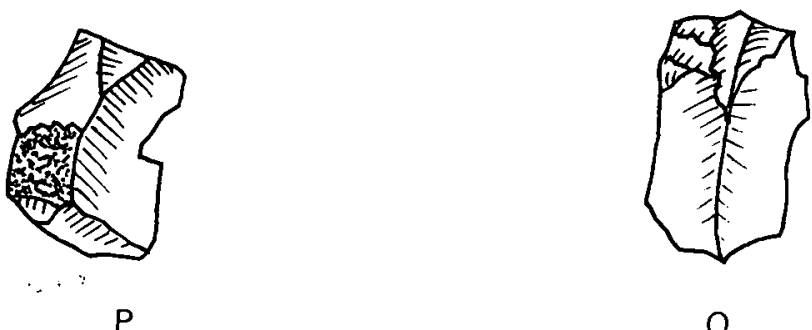

Q

Fig. 2: Cañada Honda. Industria lítica 


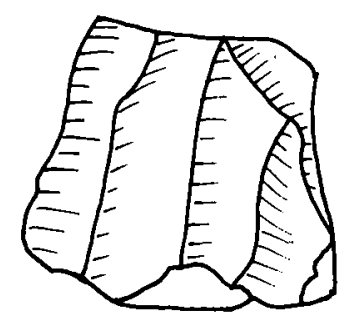

C

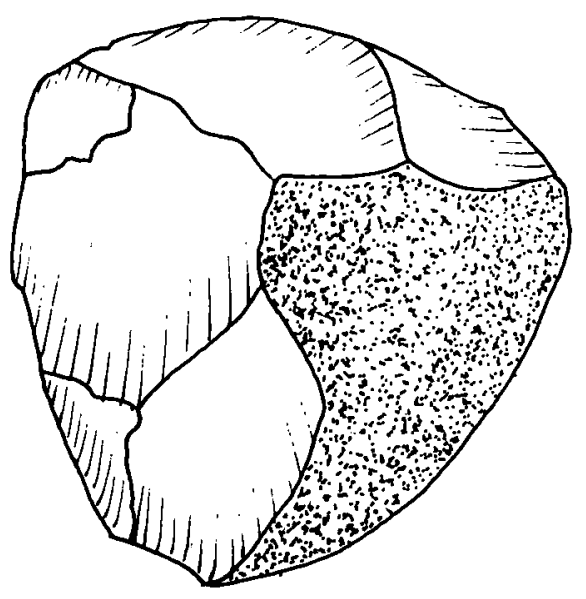

$\mathrm{F}$

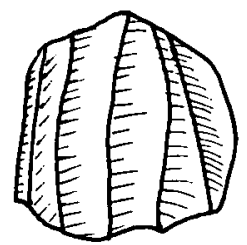

D

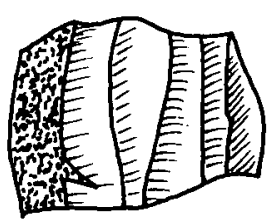

$E$
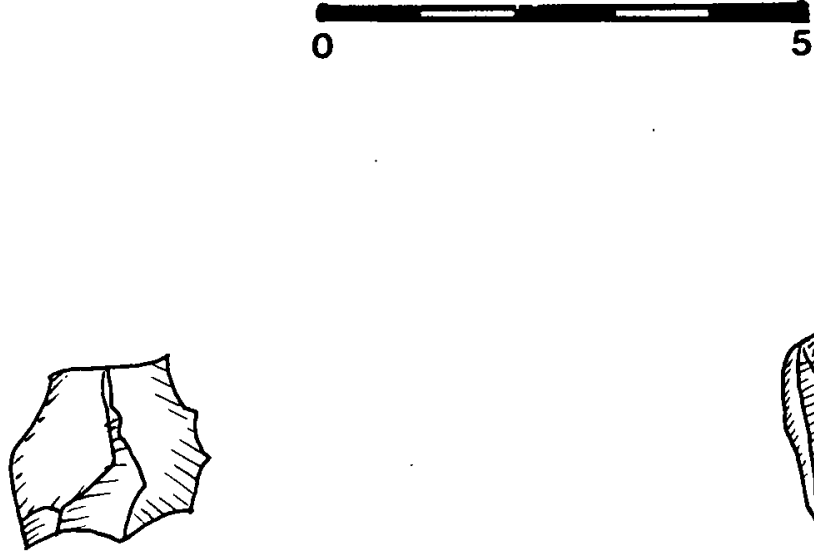

Fig. 3: Cañada Honda. Industria lítica A

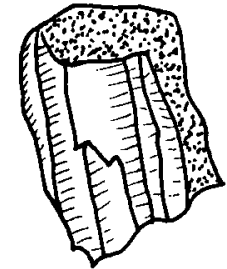

B 